\title{
Solving Health Care Facility Location Problems with New Heuristic Algorithm Method
}

\author{
Mohammad Taghi Valipour, Arman Nedjati, and Reza Kazemi
}

\begin{abstract}
In recent years, there has been much conservation about the issue healthcare location problem. In this paper we focus on emergency aspect of healthcare that related to allocate facilities. The best locations for some health care facilities are allocated according to different covering distances. We present IPSO (Improved Particle swarm optimization), as a powerful heuristic algorithm to maximizes the population assigned to a facility within the coverage distance. The proposed method was compared with the results of the LINGO software, GA. The results of this comparison show that IPSO can achieve better results for the solution in a faster time.
\end{abstract}

Index Terms-Maximum covering model, healthcare location, IPSO.

\section{INTRODUCTION}

Facility location studies are generally devoted to the location of a set of resources or service facilities to optimally serve a given set of existing customer or demand facilities.

The location of facilities is critical in both industry and health care. In industry, poorly located facilities or the use of too many or too few facilities will result in increased expenses and/or degraded customer service [1]. In healthcare system decision, any erratic decision may lead to death and disease. Any unsuitable location decision will result in undesired situations such as increased cost, capital costs, and degraded patient service. Similarly the demand allocation to these facilities has a direct impact on the whole system's efficiency. This location-allocation model plays a significant role in health service planning, as it provides a framework for investigating accessibility problems, comparing the quality (in terms of efficiency) of previous location decisions, and providing alternative solutions to change and improve the existing system[2]. In this case some models are suggested for healthcare location models; set covering model, maximal covering and model p-median model. All three models are in the class of discrete facility location models, in these models assume that there is a finite set of candidate locations or nodes at which facilities can be sited. Thus, we might represent a city by several hundred or even several thousand points or nodes.

Maximal Covering Location Problem (MCLP) first proposed by Church and Revelle [3] is one of the most common models employed in public healthcare planning due

Manuscript received November 2, 2012; revised January 10, 2013.

Mohammad Taghi Valipour and Arman Nedjati are with Industrial Engineering Department, Eastern Mediterranean University, Famagusta, TRNC, Via Mersin 10, Turkey (e-mail: mohammad.valipourr@gmail.com, arman.nedjati@cc.emu.edu.tr).

Seyedreza Kazemirazi is with Computer Engineering Department, Eastern Mediterranean University, Famagusta, TRNC, Via Mersin 10, Turkey (e-mail: kazemi.razi@gmail.com). to limited budget as it maximizes population to be covered given a limited number of fixed facilities. In a standard MCLP, one seeks location of a number of facilities on a network in such a way that the covered population is maximized. A population is covered if at least one facility is located within a pre-defined distance of it. This pre-defined distance is often called coverage radius. The choice of this distance has a vital role and affects the optimal solution of the problem to a great extent. Numerous approaches have been developed over years to solve the Maximal Covering Location Problem which can be mainly classified into exact approaches, Data analysis, Simulation, Muticriteria decision analysis, e) Heuristics, Meta-heuristics, Hybrid approaches or combinations of the above. The exact approaches or the mathematical programming approaches involve the use of techniques such as linear programming, integer programming, multi-objective optimization etc. to arrive at optimal solutions. [4] Used linear program to solve plant location. A Metaheuristic is an approach used for optimization by iteration in the neighborhood of solution space. Examples of Metaheuristics are simulated annealing, Tabu search, genetic algorithms etc. In past decade several heuristics have been designed for the capacitated maximum covering problem. Resende [5] studied the performance of GRASP in solving the maximal covering problem. De Assis Correa, Lorena, and Ribeiro [6] analyzed the probabilistic version of MCLP in which there is one server per center. They used a combination of column generation and covering graph approaches in order to solve this problem. Berman and Krass [7] considered partial coverage of customers for a general class of MCLP. Batanovic, Petrovic, and Petrovic [8] suggested maximal covering location problems in networks with uncertainty. Murray and Church [3] apply simulated annealing for location allocation problem. Tabu search for location allocation problems was investigated by Ohlemüller, Chan and Kumar [9] apply multi ant colony optimiza-tion approach for customer's allocation.

Genetic algorithm was widely applied to solve the problem because of its' unique self-organization and auto-adapted. Genetic algorithm can extremely effectively solve the multi-objectives NP complete question. Owen and Daskin [1] have used GAs to solve a complex model in strategic facility location. Shavandi and Mahlooji [10] presented a fuzzy location-allocation model for congested systems and called it fuzzy queuing maximal covering location-allocation. In this paper a new hybrid method based on particle swarm optimization to solve MCLP is proposed. The remainder of the paper is organized as follows. In Section II, we give a mathematical programming formulation for. In Section III new optimization algorithm used to solve the described. A detailed computational comparison between proposed 
algorithm and other optimization methods is discussed in Section IV. Section V contains some conclusions and summarizing.

\section{FORMULATION OF THE PROBLEM}

The following formulation, adapted from Pirkul and Schilling (1991) is used to model the problem:

$$
\begin{array}{lr}
\sum_{j \in J} Y_{J} \leq P & \sum_{\mathrm{i} \in \mathrm{I}} \mathrm{c}_{\mathrm{ij}} \mathrm{a}_{\mathrm{i}} \mathrm{x}_{\mathrm{ij}} \\
\sum_{j \in J} x_{i j}=1 & \\
\sum_{j \in J} a_{i} x_{i j} \leq Y_{j} K_{j} & j \in I
\end{array}
$$

$$
x_{i j}, y_{J}=\{0,1\} \quad i \in I, j \in J
$$

where

$I$ is the index set of all demand nodes,

$J$ is the index set of all facility sites

$a i$ is the demand volume at node $\mathrm{i}$,

$K j$ is the workload capacity for a facility at site $\mathrm{j}$,

is the number of facilities to be sited,

$S$ is the maximum service distance,

$d i j$ is the travel distance from demand node $\mathrm{i}$ to facility $\mathrm{j}$,

$x_{i j k}=\left\{\begin{array}{lr}1 & \text { if } \mathrm{d}_{\mathrm{ij}} \leq \mathrm{s} \\ 0 & \text { Otherwise }\end{array}\right.$

$x_{i j k}=\left\{\begin{array}{rr}1 & \text { if demand node } \mathrm{i} \text { is served by facility } \mathrm{j} \\ 0 & \text { Otherwise }\end{array}\right.$

$x_{i j k}=\left\{\begin{array}{rr}1 & \text { if a facility is sited at } \mathrm{j} \\ 0 & \text { Otherwise }\end{array}\right.$

The objective function maximizes the population assigned to a facility within the coverage distance $S$, such that cij is equal to 1 ifd $_{\mathrm{ij}} \leq \mathrm{s}$.

\section{IMPROVED PARTICLE SWARM OPTIMIZATION}

Particle swarm optimization (PSO) is an evolutionary computation technique, introduced by Kennedy and Eberhart [11]. The main idea is based in the way birds travel when trying to find sources of food, or similarly the way a fish school will behave. The way this behavior is modeled, is that the "particles" inside the "swarm" (or population) are treated as solutions to a given problem. The solution space for that problem is where the particles will be moving or traveling through, searching for the best solutions to the problem. The particles will travel following two points in the space; a leader in the swarm, which is chosen according to the global best solution found so far', and its memory. Every particle has a memory, which is the best solution visited by that specific particle [12]. According to [13] Some experimental results show that PSO has greater "global search" ability, but the "local search" ability around the optimum is not very good. In order to enhance "local search" ability of PSO, an improved particle swarm optimization was introduced in this paper, which was PSO with Mut the flowchart of the method is given in Fig . 1.

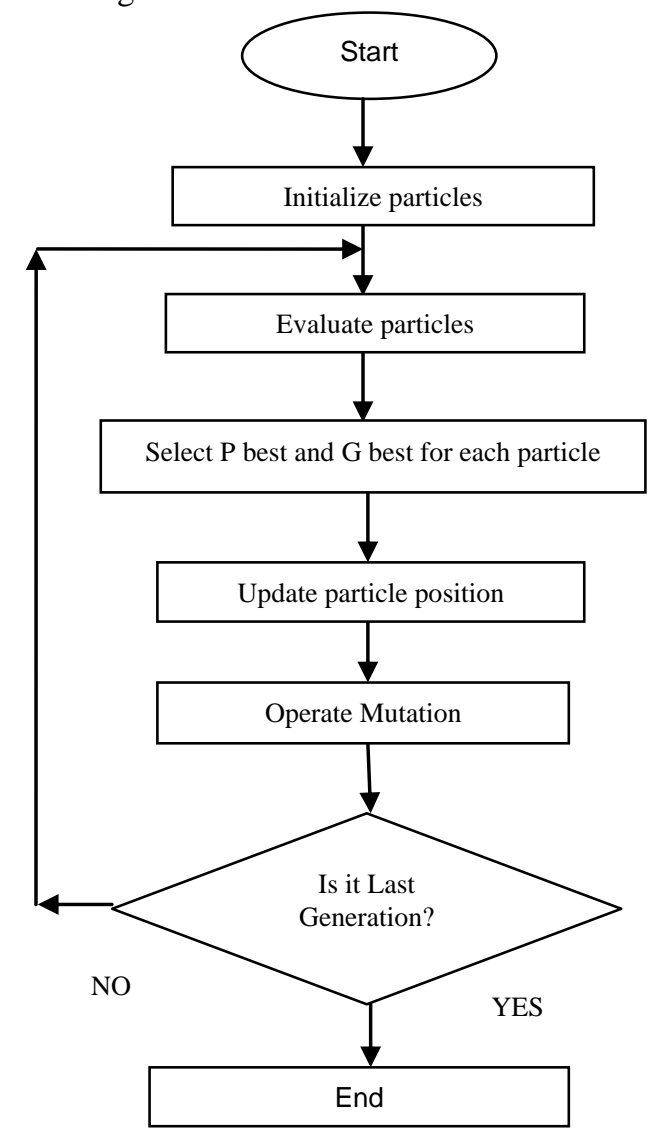

Fig. 1. Flow chart of method

\section{Computational Results}

In order to evaluate the proposed hybrid IPSO, two numerical examples are applied. The presented model is solved by the Lingo 8 software and the proposed IPSO algorithm. The proposed algorithm is coded in MATLAB in a windows XP environment. The related results are compared with the results of Lingo and GA. Note that as to our knowledge there is no recent benchmark problems with the same parameter values ( $\mathrm{S}$ and capacity values) are available for comparison. The network consists of 20 nodes and all the nodes in the network were considered to be candidates for

\begin{tabular}{|c|c|c|c|c|c|}
\hline$S$ & Utili & tion & & & LINDO \\
\hline \multirow[b]{2}{*}{100} & $\begin{array}{l}\text { MA } \\
X\end{array}$ & MIN & IPSO & GA & \multirow{2}{*}{$\begin{array}{l}\text { OPTIMAL } \\
\text { SOLUTION } \\
302,950,400 \\
329,973,800 \\
334,781,400\end{array}$} \\
\hline & $\begin{array}{l}120 \\
160 \\
200\end{array}$ & $\begin{array}{l}0 \\
0 \\
0\end{array}$ & $\begin{array}{l}300,900,216 \\
329,943,812 \\
314,766,348\end{array}$ & $\begin{array}{l}303,930,220 \\
329,973,812 \\
334,781,428\end{array}$ & \\
\hline 125 & $\begin{array}{l}120 \\
160 \\
200\end{array}$ & $\begin{array}{l}0 \\
0 \\
0\end{array}$ & $\begin{array}{l}320,349,882 \\
357,336,233 \\
338,150,008\end{array}$ & $\begin{array}{l}320,349,882 \\
347,376,253 \\
352,184,001\end{array}$ & $\begin{array}{l}320,349,900 \\
347,376,300 \\
352,184,000\end{array}$ \\
\hline 150 & $\begin{array}{l}120 \\
160 \\
200\end{array}$ & $\begin{array}{l}0 \\
0 \\
0\end{array}$ & $\begin{array}{l}346,138,633 \\
358,183,326 \\
377,391,822\end{array}$ & $\begin{array}{l}346,164,655 \\
370,183,343 \\
377,391,822\end{array}$ & $\begin{array}{l}346,168,200 \\
370,183,300 \\
390,594,500\end{array}$ \\
\hline 175 & $\begin{array}{l}120 \\
160 \\
200\end{array}$ & $\begin{array}{l}0 \\
0 \\
0\end{array}$ & $\begin{array}{l}337,975,380 \\
387,574,444 \\
400,400,000\end{array}$ & $\begin{array}{l}380,990,395 \\
390,594,424 \\
404,400,000\end{array}$ & $\begin{array}{l}380,990,500 \\
390,594,400 \\
404,400,000\end{array}$ \\
\hline
\end{tabular}
facility location as well as demand nodes.

TABLE I: COMPARISON OF TYPICAL RESULTS BETWEEN IPSO, GA, AND LINDO (BASED ON OBJECTIVE FUNCTION VALUES). 
TABLE II: COMPARISON OF TYPICAL RESULTS BETWEEN IPSO, GA, AND LINDO (BASED ON FACILITY LOCATIONS).

\begin{tabular}{|c|c|c|c|c|c|c|}
\hline $\mathrm{S}$ & Utili & atior & & & LINDO & Locations \\
\hline \multirow{2}{*}{$\begin{array}{l}10 \\
0\end{array}$} & $\begin{array}{c}\mathrm{M} \\
\mathrm{AX}\end{array}$ & $\begin{array}{l}\mathrm{M} \\
\mathrm{I} \\
\mathrm{N} \\
\end{array}$ & IPSO & GA & \multirow{2}{*}{$\begin{array}{l}\text { OPTIMAL } \\
\text { SOLUTIO } \\
\mathrm{N} \\
2,3,5,10,13, \\
15 \\
2,3,5,10,13, \\
15 \\
2,3,5,10,13, \\
16\end{array}$} & Locations \\
\hline & $\begin{array}{l}12 \\
0 \\
16 \\
0 \\
20 \\
0\end{array}$ & $\begin{array}{l}0 \\
0 \\
0\end{array}$ & $\begin{array}{l}2,3,5,10,13, \\
14 \\
2,3,5,10,13, \\
14 \\
2,3,5,10,13, \\
14\end{array}$ & $\begin{array}{l}2,3,5,10,13 \\
, 15 \\
2,3,5,10,13 \\
, 15 \\
2,3,5,10,13 \\
, 15\end{array}$ & & $\begin{array}{l}2,3,5,10,1 \\
3,15 \\
2,3,5,10,1 \\
3,15 \\
2,3,5,10,1 \\
3,15\end{array}$ \\
\hline $\begin{array}{l}12 \\
5\end{array}$ & $\begin{array}{l}12 \\
0 \\
16 \\
0 \\
20 \\
0\end{array}$ & $\begin{array}{l}0 \\
0 \\
0\end{array}$ & $\begin{array}{l}2,3,5,6,13,1 \\
9 \\
2,3,5,6,13,1 \\
9 \\
2,3,5,6,13,1 \\
5\end{array}$ & $\begin{array}{l}2,3,5,6,13, \\
19 \\
2,3,5,6,13, \\
19 \\
2,3,5,6,13, \\
15\end{array}$ & $\begin{array}{l}2,3,5,6,13,1 \\
5 \\
2,3,5,6,13,1 \\
5 \\
2,3,5,6,13,1 \\
5\end{array}$ & $\begin{array}{l}2,3,5,6,13, \\
19 \\
2,3,5,6,13, \\
19 \\
2,3,5,6,13, \\
15\end{array}$ \\
\hline $\begin{array}{l}15 \\
0\end{array}$ & $\begin{array}{l}12 \\
0 \\
16 \\
0 \\
20 \\
0 \\
\end{array}$ & $\begin{array}{l}0 \\
0 \\
0\end{array}$ & $\begin{array}{l}3,4,6,10,13, \\
19 \\
3,4,6,10,13, \\
19 \\
3,5,10,13,1 \\
6,18\end{array}$ & $\begin{array}{l}3,4,5,10,13 \\
, 19 \\
3,4,5,10,13 \\
19 \\
3,5,10,13,1 \\
6,20\end{array}$ & $\begin{array}{l}3,5,9,11,13, \\
19 \\
2,4,5,10,13, \\
19 \\
3,5,10,12,1 \\
3,19\end{array}$ & $\begin{array}{l}3,5,9,10,1 \\
3,19 \\
3,4,5,10,1 \\
3,19 \\
3,5,10,12, \\
13,19\end{array}$ \\
\hline $\begin{array}{l}17 \\
5\end{array}$ & $\begin{array}{l}12 \\
0 \\
16 \\
0 \\
20 \\
0\end{array}$ & $\begin{array}{l}0 \\
0 \\
0\end{array}$ & $\begin{array}{l}1,2,7,9,12,1 \\
3 \\
2,4,8,11,14, \\
19 \\
2,4,9,11,18, \\
19\end{array}$ & $\begin{array}{l}1,2,7,9,12, \\
13 \\
2,4,8,12,13 \\
, 19 \\
2,4,10,12,1 \\
8,19\end{array}$ & $\begin{array}{l}1,2,7,9,12,1 \\
3 \\
3,5,8,12,14, \\
18 \\
2,7,9,12,14, \\
18\end{array}$ & $\begin{array}{l}1,5,7,9,12, \\
13 \\
2,4,8,12,1 \\
3,19 \\
2,6,9,13,1 \\
8,19\end{array}$ \\
\hline
\end{tabular}

\section{CONCLUSION}

In this study which was a healthcare location problem, the emergency phase of healthcare has been focused. Allocating healthcare facilities for coverage of most of distances was main goal of this study. We identified that Improved Particle Swarm Optimization is a powerful algorithm for maximizing this coverage. Also the problem was tested with Lingo and Genetic Algorithm, so the result shows the excellence of IPSO for this kind of problems.

\section{REFERENCES}

[1] S. H. Owen and M. S. Daskin, "A note on evolution programs for solving multi-objective strategic facility location problems," Working Paper, Department of Industrial Engineering and Management Science, Northwestern University, Evanston, Illinois, 1998.
[2] S. Rahman and D. K. Smith, "Deployment of rural health facilities in a developing country," Journal of the Operational Research Society, vol. 50, pp. 892-902, 1999.

[3] R. Church and C. Re Velle, "The maximal covering location problem," Papers of Regional Science Association, vol. 32, pp. 101-118,1974.

[4] J. Brimberg and C. ReVelle, "Solving the plant location problem on a line by linear programming," TOP: An Official Journal of the Spanish Society of Statistics and Operations Research, vol. 6, issue 2, pp. 277-286, 1998.

[5] M. G. C. Resende, "Computing approximate solutions of the maximum covering problem with GRASP," Journal of Heuristics, vol. 4, pp. 161-177, 1998.

[6] F. De Assis Correa, L. A. N. Lorena, and G. M. Ribeiro, "A decomposition approach for the probabilistic maximal covering location-allocation problem," Computers \& Operations Research, vol. 36, pp. 2729-2739, 2009.

[7] O. Berman and D. Krass, "The generalized maximal covering location problem," Computers and Operations Research, vol. 29, pp. 563-581.

[8] V. Batanovic, D. Petrovic, and R. Petrovic, "Fuzzy logic based algorithms for maximum covering location problems," Information Sciences, vol. 179, pp. 120-129, 2002.

[9] T. S. Chan Felix and Kumar Niraj, "Effective allocation of customers to distribution centres: A multiple ant colony optimization approach," Robotics and computer-integrated manufacturing, vol. 25, pp. 1-12, 2009.

[10] H. Shavandi and H. Mahlooji, "A fuzzy queuing location model with a genetic algorithm for congested systems," Applied Mathematics and Computation, vol. 181, pp. 440-456, 2006.

[11] P. Kennedy and R. Eberhart, "Particle Swarm Optimization in Proceedings," IEEE International Conference 011 Neural Networks (ICNN'95), vol. 1, Piscatawa: NJ, pp. 1942-1948, 1995.

[12] M. Salazar-Lechuga and J. E. Rowe, "Particle swarm optimization and fitness sharing to solve multi-objectiveoptimization problems," IEEE pp.1204-1211, 2005.

[13] M. V. F. Pereira and L. M. V. G. Pintoand, "A new computational tool for composite reliability evaluation," IEEE Trans. Power Sytems, vol. 7, no. 1, Feb., pp. 258-264,1992.

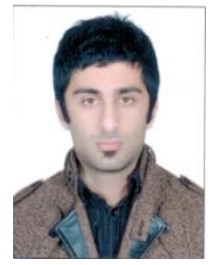

Mohammad Valipour was born in Babol, Iran, in 1988. He received the bachelor degree in Industria Engineering field in 2010 from Iran University of Science \& Technology and he is studying Master of industrial engineering in Eastern Mediterranean University. His research interest is applied operation research, healthcare management and optimization methods.He has worked as a project manager at QFID Company from 2008 until 2010.

Arman Nedjati was born in Tonekabon, Iran, in 1984. He received the bachelor degree in Industrial Engineering field in 2008 from Iran University of Science \& Technology and his master degree in Social \& Economic System in 2011. Now he is PhD student in the field of Industrial Engineering in Eastern Mediterranean University. His research interests are Intellectual Capital and Meta-heuristic methods.

Seyedreza Kazemirazi was born in Gonabad, Iran, in 1985. He received the bachelor degree in Computer Engineering field in 2010 from Azad University of Quchan branch and he is studying Computer Engineering in Eastern Mediterranean University. 